\title{
Taxonomy of purpose of Enterprise Architecture
}

Conference or Workshop Item

Accepted Version

Syynimaa, N. (2010) Taxonomy of purpose of Enterprise Architecture. In: 12th International Conference on Informatics and Semiotics in Organisations, ICISO 2010, 19 - 21 July 2010, Reading, UK. Available at http://centaur.reading.ac.uk/36289/

It is advisable to refer to the publisher's version if you intend to cite from the work. See Guidance on citing.

All outputs in CentAUR are protected by Intellectual Property Rights law, including copyright law. Copyright and IPR is retained by the creators or other copyright holders. Terms and conditions for use of this material are defined in the End User Agreement. 


\section{CentAUR}

Central Archive at the University of Reading

Reading's research outputs online 


\title{
TAXONOMY OF PURPOSE OF ENTERPRISE ARCHITECTURE
}

\author{
Nestori Syynimaa \\ Informatics Research Centre, Henley Business School, University of Reading, UK \\ Department of Computer Science, Faculty of Technology, University of Vaasa, Finland \\ CIO, Anvia IT Ltd, Finland \\ nestori.syynimaa@gmail.com
}

Keywords: Enterprise Architecture, Grounded Theory, Semiotic framework

\begin{abstract}
Initial phase of all Enterprise Architecture (EA) initiatives is important. One of the most crucial tasks in that phase is to sell EA to the top management by explaining its purpose. In this paper, by using semiotic framework we show that there is a clear gap between the definition of EA and its purpose. Contribution of this paper is a taxonomy that expands knowledge of pragmatics of EA, and that can be used as a tool for explaining the purpose of EA. Grounded theory is used to form the taxonomy. Data is collected from a discussion group used by EA practitioners. Results indicate that the purpose of EA is to meet organisations' stakeholder's goals and to create value to organisation. Results are in line with current literature. Most interesting result is that EA practitioners seem to realise that technical solutions are not the purpose of EA, but means for fulfilling it.
\end{abstract}

\section{INTRODUCTION}

For Enterprise Architecture (EA) initiative, it is crucial to sell EA to top management (Schekkerman, 2004, p. 103; TOGAF, 2009, p. 83). The lack of management buy-in is seen as one of the main reasons for EA initiatives to fail (Perks \& Beveridge, 2003, p. 142). Even though EA itself can be used as a tool to bridge a communication gap between IT and business (Lankhorst, 2009, p. 11), it is still challenging to explain why EA should be used. Thus, motivation for this paper is to find out how to explain the purpose of EA. Contribution to the body of knowledge of EA is a taxonomy of purpose of $\mathrm{EA}$, based on empirical qualitative research on EA practitioners' view to EA.

Strategy of this paper is following. First we introduce the semiotic framework. Secondly we look for current definitions of EA and discuss on them from semiotics point of view. Thirdly we conduct an empirical research on practitioners' view on EA. Lastly we present results and conclusions.

This paper is a part of a larger research for understanding the nature of Enterprise Architecture.

\section{METHODOLOGY}

Purpose of this paper is to construct a theory of the purpose of EA. To form such a theory, we will use data of EA practitioners' view to the purpose of EA by utilising Grounded Theory (GT) application by Pandit (1996). He introduces five distinct phases on GT which are research design, data collection, data ordering, data analysis and literature comparison. The first phase, research design, contains two steps. First step is to review current literature to form a research question. Second step on this phase, and next two phases, data collection and data ordering, are not relevant since we are using data already available. This is explained later on this paper. Data analysis phase is where the data is analysed using different types of coding. When data analysis reaches saturation point, which is the point where the value of new data is minimal, theory building process is considered to be completed. Last phase, literature comparison, is to compare the emerged theory to current theories and discuss about similarities or differences.

Qualitative research approach was selected due to explorative nature of the research problem. Taxonomy is used to present the emerging theory as 
it captures both the concepts and their relations to each other.

\section{THE SEMIOTIC FRAMEWORK}

Semiotics is about information science. Eco (1976, p. 7) defines semiotics as "..concerned with everything that can be taken as a sign". In the context of semiotics, a sign can be for instance a word, a sentence, a picture, a blueprint, even a gesture. Semiotics has been studied for a decades. Populous semiotics framework from Stamper can be seen in Figure 1. Many of today's literature is based on Stamper's framework (Beynon-Davies, 2009; Liu, Clarke, Andersen, \& Stamper, 2001).

To better understand semiotics, let's define some key concepts seen in Figure 1. Pragmatics is about the purpose of communication, in other words, why we are communicating or what we are trying to accomplish by communicating. Semantics is about the meaning of messages or signs, in other words, definitions about things. Syntactics is about the structure of the messages or signs, such as a grammar of a language. Empirics is about the medium used for communication (Barron, Chiang, \& Storey, 1999; Beynon-Davies, 2009; Liu, 2000, pp 26-35).

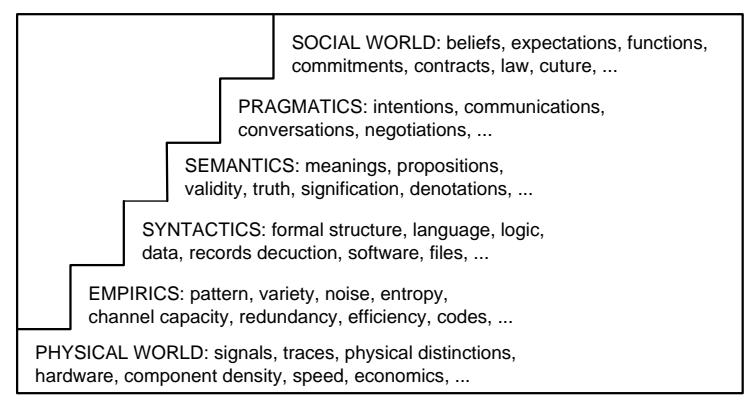

Figure 1: Adapted Stamper's (1973) Semiotic ladder (cited by Liu, 2000, p. 27).

\section{DEFINITION OF ENTERPRISE ARCHITECTURE}

Enterprise Architecture (EA) has multiple definitions on current literature. The term Enterprise Architecture consists of two distinct terms, enterprise and architecture. In the context of EA, enterprise is defined as a whole or part of an organisation that has a common goal (TOGAF, 2009 , p. 5). In this sense, enterprise can be anything from a workgroup to a global corporation. Architecture has also a number of definitions in the context of EA.

John Zachman (1997) defines architecture as "..that set of design artifacts, or descriptive representations, that are relevant for describing an object such that it can be produced to requirements (quality) as well as maintained over the period of its useful life (change)".

ISO/IEC 42010: 2007 defines architecture as "The fundamental organization of a system, embodied in its components, their relationships to each other and the environment, and the principles governing its design and evolution',

In TOGAF (TOGAF, 2009, p. 9), architecture has two meanings depending upon the context (i) "A formal description of a system, or a detailed plan of the system at component level to guide its implementation" and (ii) "The structure of components, their inter-relationships, and the principles and guidelines governing their design and evolution over time".

Federal Chief Information Officer Council of United States defines Enterprise Architecture as (CIO Council, 2001, p. 5) "...a strategic information asset base, which defines the mission, the information necessary to perform the mission and the technologies necessary to perform the mission, and the transitional processes for implementing new technologies in response to the changing mission needs. An enterprise architecture includes a baseline architecture, target architecture, and a sequencing plan".

As a summary of previous definitions, taxonomy of Enterprise Architecture by The Finnish Ministry of Finance (ValtIT, 2007) can be seen in Figure 2.

Pulkkinen summarises EA (Pulkkinen, 2008, p. 46) as "The management of the ICT assets as enterprise resources", "Planning developments of these assets and developments enabled with them, like business models, services or processes", "Collaboration of different groups; first and foremost the business and the ICT managers in the enterprise", "Managerial activity, meaning decision making", "Recording and describing the ICT resources and evaluating them for the decisions to be made", "Scanning for new technology enablers as part of the environment information the enterprise is collecting for its strategic management", "Planning development steps both for the business and the supporting ICT, according to the strategies of the enterprise."

All of the previous definitions are similar to each other in a sense that they are on high abstraction level. Pulkkinen's summary, however, introduces some characteristics of EA that are more practical, such as the management of ICT assets and scanning 


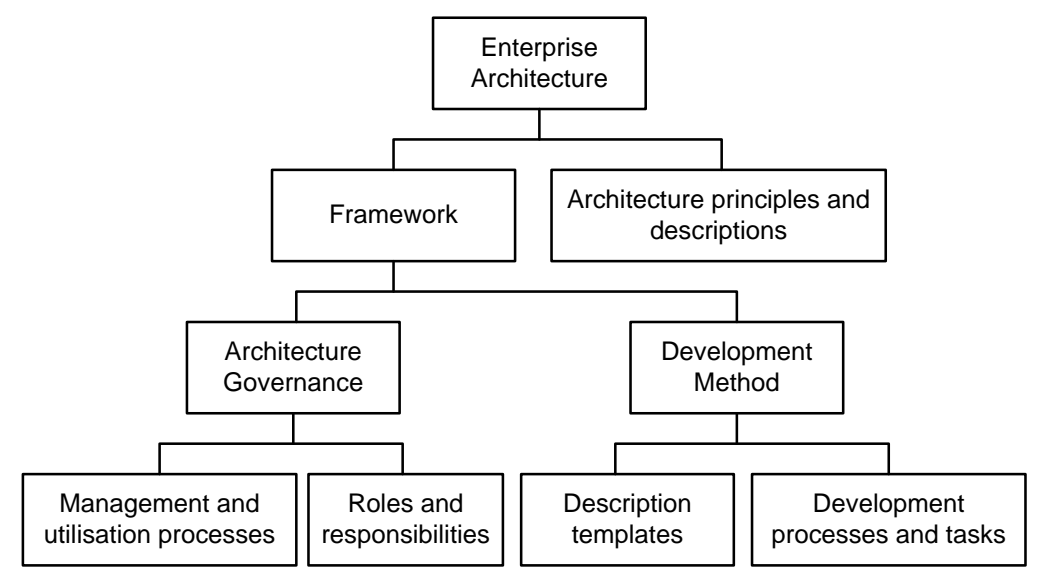

Figure 2: Taxonomy of Enterprise Architecture (ValtIT, 2007) (translated).

of new technology assets. All definitions do share two common concepts, (i) "evolution" - a managed change over time, and (ii) formal description of an organisation at a specific time.

Let's examine EA from the semiotics point of view using Stamper's semiotic ladder. The two concepts found in the current EA literature defines what EA is. Therefore we can say that we do know EA's semantics. Moreover, current EA frameworks, such as TOGAF, contains a set of EA deliverables which are used as a common language to describe EA of a given organisation from a given viewpoint. Thus, we can say that current literature also contains EA's syntactics. What is missing in the current literature is a link to EA's pragmatics. As already noted, it has been found that the support of top management of an organisation is crucial to the success of EA initiatives. It has also been found that managers do not understand what EA is (Rafidah, Dahalin, Dahari, Kamaruddin, \& Abdullah, 2007). Logical argumentation for the importance of pragmatics is that if managers do not understand the purpose of EA, they do not provide support for it. A place to look for pragmatics of EA is the social world of EA practitioners. There is some literature that can be argued to state the purpose of EA (see for example Pavlak, 2006; Sims, 2005). However, these references are applicable in the social world of EA practitioners and cannot be transferred to the social world of managers as is. Thus, there is a need to find out the purpose of EA on the conceptual level. This is also the basis for our research question:

"How does Enterprise Architecture practitioners perceive the purpose of Enterprise Architecture?"

\section{DATA COLLECTING}

Data used in this paper was collected from a discussion group in www.linkedin.com, a social network used by professionals in various fields. In October 2009, a question was posted on a discussion group called "The Enterprise Architecture Network". According to group's profile (LinkedIn, 2010), it is for people into Enterprise Architecture. The question posted was "Describe the purpose of EA in one 160 character SMS message (including spaces, punctuation and carriage returns)?" (Smith, 2009). The data used in this paper was collected from those discussions between October and December 2009. Only responses that were actual answers to the announced question are included in the data analysis, general comments and discussions were discarded. There were 125 individual contributors and 155 definitions or statements. Total number of members in the discussion group is about 40,000 so respondents represents about 3 percent of the total population of group members. The discussion group was still active on 27th February 2010, while there were more than 1,200 responses. Distribution of respondents' roles can be seen in Table 1.

Table 1: Respondents' roles.

\begin{tabular}{|c|c|c|}
\hline Role & $\mathrm{n}$ & $\%$ \\
\hline IT expert, specialist or professional & 3 & $2 \%$ \\
\hline $\begin{array}{c}\text { EA, software or systems Architect } \\
\text { or Consultant }\end{array}$ & 75 & $60 \%$ \\
\hline IT manager, director, or executive & 33 & $26 \%$ \\
\hline Other / unknown & 14 & $11 \%$ \\
\hline Total & 125 & $100 \%$ \\
\hline
\end{tabular}




\section{ANALYSIS}

Data analysis was broken down to three phases. In the first phase, data was reviewed and some initial notes on key concepts were made. On the second phase, data was analysed in more detail. Each response was analysed using microanalysis (Strauss \& Corbin, 1990, p. 57)

Responses included a number of statements of the purpose of EA. For instance "To make organizational change less time and money consuming", "The purpose of EA is to ensure digitised organisations meet or exceed customer and shareholder expectations", and "To Align Business and IT". The first response indicates that the purpose of EA is to decrease the amount of time and money while conducting organisational change. Anything that helps organisation to use less resources creates value to the organisation. In this case, value is created by making organisation more agile using EA. Second response indicates that the purpose of EA is to meet or exceed customer and shareholders expectations. In other words, purpose is to meet organisation's stakeholders' goals. Third response states that EA's purpose is to align business and IT. By aligning IT and business, organisations tries to create value. Value is not in this case necessarily created by efficiency, but by agility, since after alignment IT is more responsive to business changes and vice versa.

It is noteworthy to mention that some responses actually stated what EA is, not its purpose, this can also be seen on findings. For instance, one of the responses were "EA is optimal enterprise business process, information and technology asset management tuned to meet customer and shareholder needs in relevant time frame". This implies that EA is a process that aims to fulfilment of certain needs. Merriam-Webster's dictionary defines process as "a series of actions or operations conducing to an end". So process can be seen as an endeavour that ends at some point. According to the response, this point is when needs are fulfilled. Another response was "EA is a business planning method that ensures companies execute informed, integrated (business and IT), strategically aligned change programs". This response has more meanings than the first one. It implies that without EA, change programs are not necessary strategically aligned. Moreover, strategically aligned change programs are somehow "good for the company", or in other words, they create value. MerriamWebster's dictionary defines strategy as "a careful plan or method: a clever stratagem" and as "the art of devising or employing plans or stratagems toward a goal". Strategy is defined usually by organisation's management, owners, or other stakeholders. Although these responses were definitions of EA, they also revealed what its purpose is.

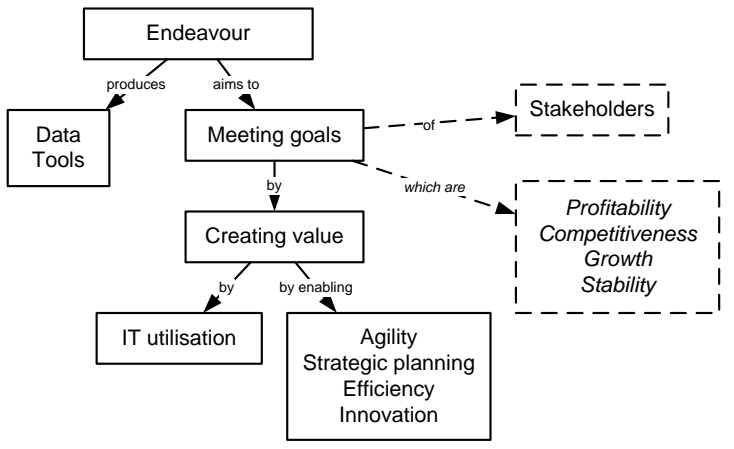

Figure 3: Findings.

Findings from the second phase can be seen in Figure 3. Data suggests that EA is seen as an endeavour aiming to reach organisational goals set by its stakeholders. Those goals are met by creating value to organisation. EA is a tool or a method, which produces a description of the enterprise.

On third phase, categories were formed based on findings. By using axial coding some categories were combined and irrelevant ones were discarded. First version of emerging taxonomy can be seen in Figure 4. As it can be seen, the main category is Enterprise Architecture, and under that there are four subcategories. First two categories, Meets stakeholders' goals and Creates value are categories about the purpose of EA. Two remaining categories are about the definition of EA, which are not the focus of this paper. Therefore the main category was renamed to Purpose of Enterprise Architecture and Description of Enterprise and Method/tool categories were removed. It is, however, noteworthy that those categories have similarities with the taxonomy in Figure 2.

Final emerging taxonomy of the purpose of the Enterprise Architecture can be seen in Figure 5. The purpose of EA is two folded. One purpose is to meet goals of the organisation. These goals are set by organisation's stakeholders. Goals to be met are profitability, competitiveness, growth and stability. Another purpose is to create value to organisation. Value is created by agility, strategic planning, efficiency and innovation. 


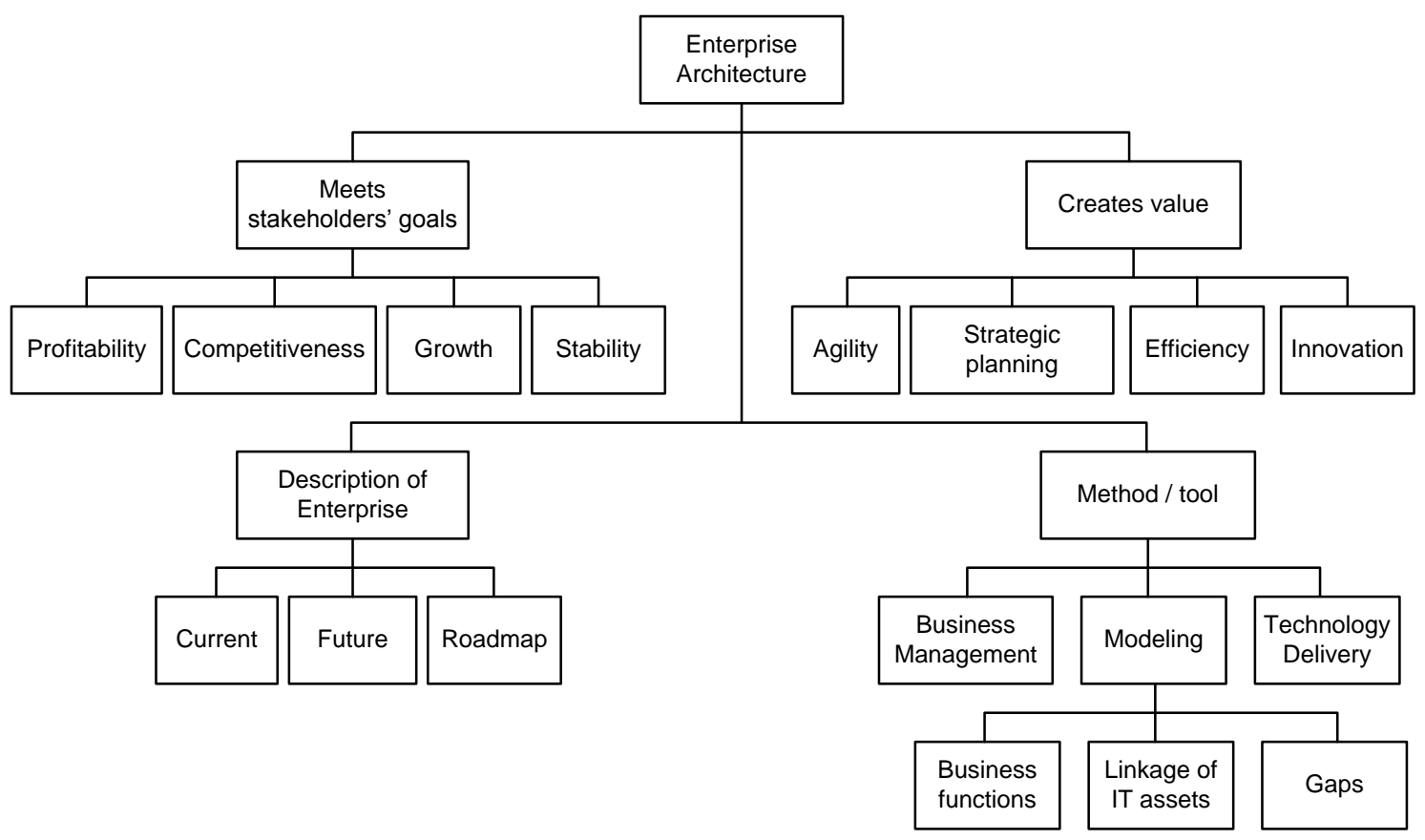

Figure 4: Initial emerging taxonomy.

\section{COMPARISON WITH CURRENT LITERATURE}

According to Sims (2005), EA's purpose is to help IT to achieve its goals. These goals are time to market, responsiveness, agility, flexibility and quality. Goals are met by designing environment that reduces the effort required to implement business applications. Sims' EA's purpose is in line with the emerging taxonomy. According to him, EA's purpose is to achieve stakeholders' goals. In this case, stakeholder is IT department. Sims point of view to EA is application development. His goals actually refers to value that application development should create. These values are also in line with the emerging taxonomy. Responsiveness and flexibility are characteristics of agility. Therefore these values along with agility go under Agility category. As quality can be understood as organisational efficiency, it goes under Efficiency category.

According Pavlak (2006), purpose of EA is to determine the relationship between business processes and information systems. This aims for business process automation. Business processes are to execute business strategy, which is typically defined by top management. Pavlak's definition for EA's purpose fits perfectly to the emerging taxonomy. EA's purpose is to execute strategy (a goal), which is defined by top management (stakeholder). EA creates value by identifying information systems that enables business processes to be automated, or in other words, making them more efficient.

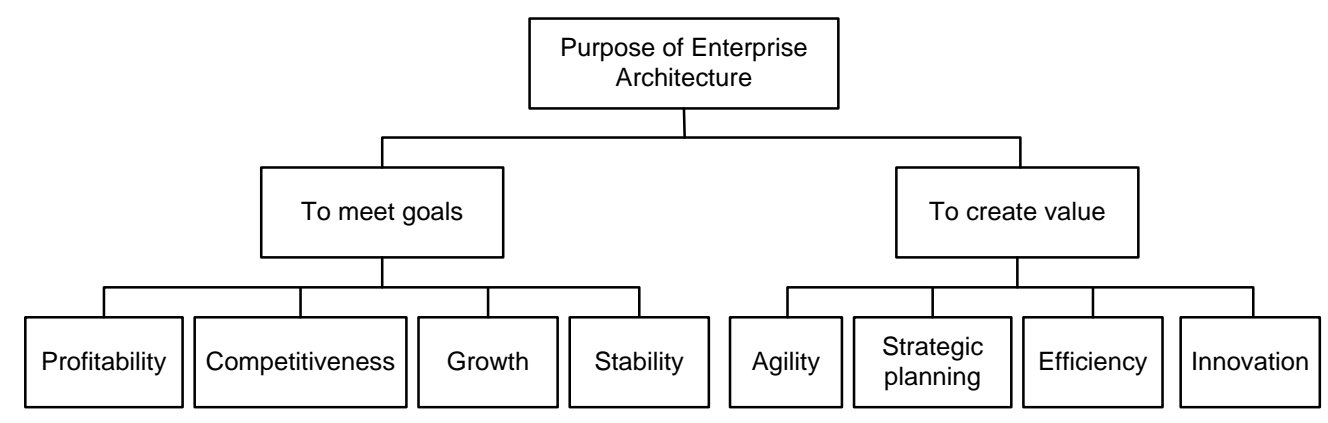

Figure 5: Emerging taxonomy of purpose of Enterprise Architecture. 
According to TOGAF (2009, p. 6), the purpose of EA is to optimise organisations processes so that they are responsive to change and execute business strategy. Furthermore, EA's purpose is to achieve competitive advantage. Those descriptions of EA's purpose are in line with the emerging taxonomy. TOGAF's EA's purpose is to optimise processes (create value by making processes more efficient), to execute business strategy (to meet goals) and to keep organisation competitive.

Zachman's (1997) framework has a motivation column, that answers to a question why? In other words, what is the purpose of the particular architecture. Top rows of the framework contains reasons like Major Business Goals, Critical Success Factor, Business Objective and Business Strategy. These all are goals, which in enterprise context are usually for example profitability, competitiveness, growth and stability. Therefore it can be argued that Zachman's framework is in line with the emerging taxonomy.

\section{RESULTS AND CONCLUSIONS}

Based on the emerging taxonomy, the purpose of EA is (i) to meet goals of organisation's stakeholders, and (ii) to create value to organisation. Thus, EA practitioners realises that technical solutions are not the purpose of EA, but means for fulfilling it. Moreover, as comparison of emerging taxonomy to current literature indicated no differences, EA practitioners can be argued to perceive the purpose of EA correctly on conceptual level. Therefore it can also be argued that the emerging taxonomy presented in this paper can be used as tool for explaining the purpose EA to organisation's top management.

A limitation of this study is that the data used in analysis is not collected in controlled manner. In their nature, discussion groups are open to everyone to post responses. In this case, the discussion group was focused entirely on EA. Although there are over 40,000 members in the group, it is not fair to argue that members of the group represent the whole population of EA practitioners. The data used in this paper $(n=125)$ is not collected using random sampling. However, the saturation point in coding was reached by data used, which indicates that the data is reliable. As can be seen in Table 1, respondents were professional practitioners of EA. Moreover, emerging taxonomy is in line with the current literature. Therefore it can be argued that the data and results are valid.

\section{ACKNOWLEDGEMENTS}

Author would like to express his grateful thanks to the author of the discussion group, Mr Kevin Smith, for collecting and giving access to the data used in this paper. Author also expresses thanks to anonymous reviewers who helped to improve this paper.

\section{REFERENCES}

Barron, T., Chiang, R., \& Storey, V. (1999). A semiotics framework for information systems classification and development. Decision Support Systems, 25, 1-17.

Beynon-Davies, P. (2009). Formated technology and informated action: The nature of information technology. International Journal of Information Management, 29(4), 272-282.

CIO Council. (2001). A Practical Guide to Federal Enterprise Architecture. Available at http://www.cio.gov/documents/bpeaguide.pdf.

Eco, U. (1976). A theory of semiotics: Bloomington: Indiana University Press.

Lankhorst, M. (2009). Enterprise architecture at work: Modelling, communication and analysis: Springer-Verlag GmbH.

LinkedIn. (2010). The Enterprise Architecture Network's Group Profile. Retrieved 27th February, 2010, from http://www.linkedin.com/groups?about=\&gid=3 $6781 \&$ trk=anet_ug_grppro

Liu, K. (2000). Semiotics in Information Systems Engineering: Cambridge University Press.

Liu, K., Clarke, R., Andersen, P., \& Stamper, R. (2001). Information, organisation, and technology: studies in organisational semiotics: Kluwer Academic Pub.

Pandit, N. (1996). The creation of theory: A recent application of the grounded theory method. The qualitative report, 2(4), 1-20.

Pavlak, A. (2006). Enterprise Architecture: Lessons from Classical Architecture. Journal of Enterprise Architecture, 2(2), 20-27.

Perks, C., \& Beveridge, T. (2003). Guide to enterprise IT architecture: Springer Verlag.

Pulkkinen, M. (2008). Enterprise Architecture as a Collaboration Tool. Jyväskylä Studies in Computing, 93, 134.

Rafidah, A. R., Dahalin, Z. M., Dahari, R., Kamaruddin, S. S., \& Abdullah, S. (2007). 
Enterprise Information Architecture (EIA): Assessment of Current Practices in Malaysian Organizations. Paper presented at the HICSS-40. 40th Annual Hawaii International Conference on System Sciences, Waikoloa, Hawaii, USA.

Schekkerman, J. (2004). How to Survive in the Jungle of Enterprise Architecture Frameworks: Creating or Choosing an Enterprise Architecture Framework: Trafford Publishing.

Sims, O. (2005). The Purpose of Enterprise Architecture. Enterprise Architecture Advisory Service, 8(6).

Smith, K. (2009). The Enterprise Architecture Network discussions: Describe the purpose of EA in one 160 character SMS message. Retrieved 2nd January, 2010, from http://www.linkedin.com/groupAnswers?viewQu estionAndAnswers $=\&$ gid $=36781 \&$ discussionID $=8240387$

Stamper, R. (1973). Information in business and administrative systems: John Wiley \& Sons, Inc. New York, NY, USA.

Strauss, A., \& Corbin, J. (1990). Basics of qualitative research: Sage Publ.

TOGAF. (2009). TOGAF Version 9: Van Haren Publishing.

ValtIT. (2007). Finnish National Enterprise Architecture Development Project - Final Report, Unified model for holistic planning of functionality and information systems Available from http://www.vm.fi/julkaisut

Zachman, J. (1997). Enterprise architecture: The issue of the century. Database Programming and Design, 10(3), 44-53. 